\title{
Uso de psicotropicos pelo enfermeiro: sua relação com o trabalho
}

\author{
Psychotropic use by nurses: relationship with work
}

\author{
Graziela Clementina Galvani Vieira,, ${ }^{1,2}$ Raquel Lima De Brida,, ${ }^{1,2}$ Regiane da Silva Macuch, ${ }^{2}$ Ely Mitie Massuda, ${ }^{2}$ \\ Gabriele Pereira Preza' \\ ${ }^{1}$ Faculdade Integrado de Campo Mourão, PR, Brasil. \\ ²entro Universitário de Maringá (UniCesumar), Maringá, PR, Brasil.
}

Recebido em: 26/07/2016 / Aceito em: 27/09/2016 / Publicado em: 30/09/2016

graziela.vieira@grupointegrado.br

\section{RESUMO}

O processo de trabalho da enfermagem é complexo e envolve o bem-estar físico e mental, como também a promoção, manutenção e prevenção a saúde integral dos profissionais de enfermagem. Objetivo: identificar entre os profissionais enfermeiros se fazem uso de medicação psicoativa, sobre a sobrecarga de trabalho e o conhecimento que estes profissionais possuem em relação aos fatores de risco que estão expostos no ambiente de trabalho. Método: trata-se de uma pesquisa qualitativa do tipo descritivo-exploratória, realizada em um Hospital Filantrópico na cidade de Campo Mourão, Paraná. Participaram da pesquisa 17 enfermeiros (as). Resultados e considerações finais: o estudo aponta que os enfermeiros fazem uso de medicação psicoativa por se encontrarem no limite com sua saúde física e psíquica, devido à demanda de trabalho e fatores de risco que se expõem em suas atividades laborais. Os enfermeiros passam por níveis de estresse elevados o que os condicionam ao uso de medicações, algumas vezes sem orientação médica, levando a uma qualidade de vida prejudicada.

Palavras-chave: Estresse Laboral; Sobrecarga de Trabalho; Enfermagem; Substâncias Psicoativas.

\section{ABSTRACT}

The nursing work process is complex and involves physical and mental well-being, as well as the promotion, maintenance and prevention aspects of health of nursing professionals. Objective: identify among nurses' professionals the use of psychoactive medication on the workload and the knowledge of these professionals about the risk factors that they are exposed in the work- place. Method: this is a qualitative study of descriptive exploratory type, held in a Charitable Hospital in the city of Campo Mourão, state of Paraná, Brazil. Participants were 17 nurses. Results and closing remarks: the study shows that nurses make use of psychoactive medication because they are within the limits with their physical and mental health, due to the demand for labor and risk factors that are exposed in their work activities. Nurses undergo high stress levels which lead to the use of medications, sometimes without medical advice, leading to impaired quality of life.

Keywords: Stress Labor; Work overload; Nursing; Psychoactive substances.

\section{INTRODUCÃ̃O}

O trabalho é considerado uma atividade de sobrevivência, pois de modo simples e concreto é a forma mais complexa da expressividade do ser humano; sendo assim, uma necessidade de expressão que envolve a busca de seu espaço. ${ }^{1}$

Todo e qualquer trabalho pode trazer, tanto a satisfação, ao trabalhador como também promover descontentamento social, pessoal, monotonia, de tarefas e atividades, falta de valorização e sobrecarga de trabaIho, sendo estes os fatores que influencia em muito a interrupção do exercício profissional. ${ }^{1}$

$O$ processo de trabalho da enfermagem faz parte do processo de trabalho em saúde, necessitando de estudos, ações e formulação de estratégias para uma melhor realização de cuidados seguros ao cliente e à valorização do profissional. ${ }^{2}$ Existe um crescimento do número de profissionais da saúde que adoecem por questões profissionais, relacionadas ao ambiente de 
trabalho, carga de trabalho e entre outros. A enfermagem, por exemplo, encontra-se exposta a fatores de risco de natureza física (ruído, vibrações, pressões anormais, temperaturas extremas, radiações etc.), química (poeiras, fumos, névoas, neblinas, gases, vapores que podem ser absorvidos por via respiratória ou através da pele etc.) e biológica (bactérias, fungos, bacilos, parasitas, protozoários, vírus, entre outros).3,1

Atualmente, as condições de trabalho da equipe de enfermagem, principalmente nos hospitais, têm sido consideradas impróprias, passando a ser geradora de riscos à saúde, formando um conjunto de problemas que engloba a remuneração inadequada, a acumulação de escalas de serviço, o aumento da jornada de trabalho seguido de plantões, características tensiógenas dos serviços de saúde, tanto pela natureza do cuidado prestado às pessoas em situações de risco, quanto pela divisão social do trabalho. ${ }^{2}$

Segundo a Organização Mundial da Saúde (OMS) em 1995, o estresse foi considerado uma preocupação mundial relacionado à saúde; dessa forma, diante de tantos estudos, foram surgindo relatos sobre uma nova Síndrome chamada Burnout, que se caracteriza da relação com o trabalho, afetando com maior incidência os profissionais da área da saúde, educação e serviços humanos, destacando-se os profissionais da área da enfermagem. ${ }^{4,5}$

O estresse acomete o profissional de forma tão avançada a ponto que o indivíduo utilize substâncias psicoativas, na tentativa de aliviar as tensões diárias vivenciadas, pois o estresse pode ser caracterizado como um desgaste do organismo, relacionado a situações em que o indivíduo é forçado a enfrentar, causando irritação e negação. Dessa forma, o trabalho em âmbito hospitalar, torna-se contribuinte significativo para ocasiões de esgotamento e de fadiga física e mental.,

Segundo a Organização Mundial de Saúde (OMS) os transtornos depressivos ou simplesmente a depressão é identificada com a quarta maior causa de impacto entre todas as doenças no mundo, com altas taxas de morbidade e mortalidade superando as doenças crônicas, hipertensão, diabetes e doenças pulmonares. ${ }^{6}$

Este sofrimento psíquico é comum entre esses profissionais e, como forma estratégica para aliviar a pressão sentida, os trabalhadores de enfermagem acabam utilizando os psicofármacos. Médicos e enfermeiros são os profissionais que tem mais tendências a se tornarem dependentes das drogas psicoativas. ${ }^{6}$

O presente estudo levanta pontos relevantes, e fatores que favorecem o desenvolvimento do estresse laboral que, como consequências levam o profissional a buscar alternativas medicamentosas para restabelecer seu equilíbrio mental. A pesquisa tem relevância na identificação dos principais fatores contribuintes para a saúde do trabalhador enfermeiro, de modo a identificar e expor ações e estratégias que colaborem na reorganização da função e responsabilidades do profissional enfermeiro. Desta forma, o objetivo da pesquisa é identificar entre os profissionais enfermeiros de uma instituição filantrópica se fazem uso de medicação psicoativa, a ocorrência de sobrecarga de trabalho e o conhecimento que estes profissionais possuem em relação aos fatores de risco que estão expostos no ambiente de trabalho.

\section{MÉTODO}

Trata-se de uma pesquisa qualitativa do tipo descritivo-exploratório. A pesquisa qualitativa; verifica a relação entre o mundo real e o sujeito que não podem ser traduzidos em números. ${ }^{8}$

A pesquisa foi realizada em um Hospital Filantrópico na cidade de Campo Mourão, Paraná. Esta instituição integra o Sistema de Saúde da Macrorregião Noroeste do Estado do Paraná e faz parte da $11^{\mathrm{a}} \mathrm{Re}$ gional de Saúde, que além de Campo Mourão, atende mais 24 municípios da Mesoregião Centro Ocidental do Paraná, para os quais esta instituição é referência em atendimento para usuários do Sistema Único de Saúde (SUS), bem como da Central de Regulação de Leitos do Estado do Paraná e Serviço de Atendimento Móvel de Urgência. Possui atualmente 142 leitos, dos quais 115 estão credenciados ao (SUS), subdivididos em Clínica Médica e Cirúrgica; Clínica Médica Oncológica e Cirúrgica; Pediatria; Maternidade; Unidade de Terapia Intensiva Adulto; Unidade de Terapia Intensiva Neonatal e Unidade de Terapia Intensiva Pediátrica.

O hospital conta hoje com serviços exclusivos na região, que compreende 25 municípios, somando mais de 330 mil habitantes. Sendo referência para assistência em Unidade de Alta Complexidade em Oncologia - UNACON com serviço de radioterapia, Gestação de Alto Risco, Terapia Intensiva Neonatal-Pediátrica e tratamento para Doenças Sexualmente Transmissíveis - DST/HIV.

Mensalmente, atende-se uma média de 6,5 mil pessoas entre atendimentos ambulatoriais e internamentos. Para isto, a instituição conta com um quadro de funcionários de 440 funcionários, sendo que aproximadamente 200 funcionários são profissionais da enfermagem.

Os sujeitos da pesquisa foram os profissionais enfermeiros, que atuam nas diferentes unidades da instituição nos turnos de trabalho matutino, vespertino e noturno. O número de participantes foi delimitado conforme a saturação das respostas ou pela não concordância com o Termo de Consentimento Livre e Esclarecido. A instituição conta com um total de 30 enfermeiros, no qual participaram da pesquisa 17 , sendo que dos outros 13 enfermeiros, 03 recusaram, 02 estavam em período de férias, 01 de licença maternidade, 01 de afastamento médico e outros 03 não conseguiram participar, justificando a demanda de serviço, mesmo após três tentativas do pesquisador, em comparecimento na data e horário agendado.

A coleta de dados ocorreu no mês de outubro de 2015, através de entrevista individual semi-estruturada gravada com aparelho Iphone 5 s e transcritas na íntegra. $\mathrm{O}$ instrumento de coleta de dados conteve questões objetivas e subjetivas pertinentes ao tema. Com base nos relatos dos profissionais enfermeiros que participaram deste estudo foi possível a formação de três categorias para análise dos dados: a) Fatores de Risco no Ambiente de Trabalho. b) A sobrecarga de trabalho interfere na qualidade de vida e no ambiente laboral. c) Uso de Psicotrópicos, sua relação com o trabalho.

Para análise dos dados foi utilizado à análise de conteúdo proposta por Minayo. ${ }^{8}$ Para manter o sigilo dos sujeitos foram atribuídos codinomes em suas falas. Este projeto seguiu os preceitos e aspectos éticos 
contemplados na resolução 466/12 que regulamenta as pesquisas envolvendo seres humanos e teve aprovação do Comitê de Ética e Pesquisa da Faculdade Integrado de Campo Mourão, Paraná com protocolo de aprovação $\mathrm{n}^{\circ} 1.190 .916$

\section{RESULTADOS E DISCUSSÃO}

A apresentação e discussão dos resultados se realizará em dois momentos. Primeiramente serão apresentadas as informações gerais de caracterização dos sujeitos do estudo e no segundo momento os dados serão apresentados por categorias.

A população pesquisada foi de 17 participantes, dos quais 16 são do sexo feminino, sete com formação há mais de cinco anos e os outros 10 há menos de cinco anos. Nove possuem pós graduação, oito trabalham no período matutino, quatro no vespertino e cinco no período noturno. A média idade foi de 27,9 anos de idade, variando dos 23 aos 47 anos. No período da pesquisa, cinco profissionais relataram serem casados, doze solteiros, sete possuem filhos, 13 relataram ter outro vínculo empregatício e 11 serem responsáveis por mais de uma unidade assistencial em seu horário de trabalho. A carga horária de trabalho semanal são 36 horas, com plantões de 12 horas aos sábados ou domingos.

\section{Fatores de Risco no Ambiente de Trabalho}

Nesta categoria, é mostrado o conhecimento que os profissionais de enfermeiros possuem em relação aos fatores de risco em que estão expostos no ambiente de trabalho. De maneira geral, os participantes da pesquisa conhecem esses fatores de risco e os associam com o alto nível de estresse gerado pela profissão, conforme demonstram os discursos a seguir:

São riscos físicos, químicos, biológicos, psicológicos, desenvolvidos através do acúmulo de responsabilidades, a falta de funcionários, condições de trabalho insuficientes, salário baixo e desrespeito médico, tudo isso gera muito es tresse. (AMARELO)

Os riscos biológicos, físicos, são bastante falados, mas o risco maior na minha opinião são os que levam ao estresse e adoecem a gente mentalmente,levando a atestados longos, que vão refletir no meu convívio com a família, na minha condição financeira e até como me enxergam aqui no trabalho. (ROXO)

Percebe-se que ao mencionarem os fatores de risco que estão expostos no trabalho, direcionam o discurso para as condições estressantes vivenciadas no ambiente de trabalho, o que causa medo de adoecer, sobrecarga de trabalho e inúmeras consequências que está situação acarretaria de forma desfavorável ao profissional de enfermagem.

Um estudo realizado no Rio de Janeiro constatou que riscos ocupacionais é o terceiro motivo de licenças de saúde por períodos iguais ou superiores há 15 dias, ou seja, transtornos que levam a alterações mentais e comportamentais que os mesmos estão expostos diariamente ocasionando prejuízos pessoais, sociais e econômicos. Neste estudo, ainda foi levantado que as condições de trabalho inadequadas podem interferir na saúde do trabalhador e também causar insatisfação profissional. $^{9}$

Os enfermeiros ainda retratam, em seus discursos, a sobrecarga de trabalho imposta no dia-a-dia no ambiente de trabalho como fator de risco.

\begin{abstract}
A sobrecarga de trabalho, gera muita cobrança, estresse na oncologia fatores de risco, que afeta o psicológico, entre outro a exposição à radioterapia e vínculo com a família. (ROSA)
\end{abstract}

A sobrecarga de trabalho em relação ao enfermeiro, o número reduzido de técnicos de enfermagem, o despreparo desses técnicos de enfermagem, acho que é um agravante que contribui para ocorrer vários riscos gerando desequilíbrio emocional. (VERDE)

Nos discursos apresentados, a sobrecarga de trabalho é vista como fator de risco e geradora de estresse. Também, a unidade que o enfermeiro atua pode ter relação com os fatores que o enfermeiro está exposto. Assim, expresso quando cita a unidade de oncologia, que é um local que atua no segmento da radioterapia e quimioterapia. Este traz riscos que são bem discutidos e outros menos abordados, como quando pacientes permanecem por períodos prolongados de internamento e ocorre a criação do vínculo, sendo que, na ocasião da perda do paciente leva ao sofrimento, comprometendo à saúde psíquica. O despreparo da equipe é um fator muito significativo para o estresse, gerando o conflito até mesmo entre os próprios profissionais.

O estreitamento do vínculo com o paciente e a família é um fator de desgaste emocional, pois quando ocorrem as perdas, principalmente por mortes são tratadas como questões negativas no trabalho. Esses trabalhadores podem enxergar tais situações, sendo comum à profissão, ou seja, como fatores inerentes à profissão, mas que os levam a criar estratégias de defesa para o enfrentamento dos riscos, para se manter a saúde mental. Mesmo tornando-se como parte do trabalho do enfermeiro, esses riscos geram adoecimento. ${ }^{9}$

A importância da identificação precoce dos desencadeadores dos estresses, para adoção de medidas e realização de cuidado com a saúde destes trabalhadores, deve ser tratada com rigor, visto que o estresse vinculado ao trabalho pode estar relacionado à alta demanda existente, ultrapassando a capacidade física e/ ou psíquica do profissional para atender tal demanda. ${ }^{10}$

A enfermagem está exposta a diversos riscos, podendo acarretar em condição negativa à saúde e desencadear acidentes nos serviços e até mesmo doenças ocupacionais, devido à sobrecarga de serviço que leva ao estresse. ${ }^{11}$

Os riscos ocupacionais no ambiente hospitalar são causados por fatores que favorecem sua ocorrência na enfermagem. Uma profissão desgastante devido à sobrecarga de atividades, acúmulo de funções e jornadas de trabalho extenuante, muitas vezes com recurso inadequado o que prejudica realizações de tarefas e condiciona o aumento de responsabilidades profissionais. Tratando-se de instituição hospitalar pública, podem ocorrer desgastes maiores no trabalhador, devido à alta 
demanda de atendimentos e subdimensionamento de profissionais. $^{12}$

\section{A sobrecarga de trabalho interfere na qualidade de vida e no ambiente laboral}

Esta categoria traz informações de como a sobrecarga de trabalho interfere na qualidade de vida e no ambiente laboral. Os enfermeiros colocam que a existência da sobrecarga de trabalho traz prejuízo no desenvolvimento das atividades laborais bem como na qualidade de sua vida. Que o fato de levar atividades do trabalho para casa, faz com que se coloquem em extensão do trabalho e não descansam no intervalo entre uma jornada e outra, além de ocorrer à privação das atividades de lazer com a família e amigos, conforme demonstrado nos discursos a seguir:

\begin{abstract}
Acabo levando o trabalho pra casa; isso, poupa-me de um tempo que poderia ter com a minha família, amigos, um período de lazer que eu poderia ter ou descansar, pra voltar renovado pro trabalho, devido levar trabalho para casa e o período que era pra você descansar você continua trabalhando. (ROXO)
\end{abstract}

Meu dia de trabalho parece que não se encerra nunca, acabo tendo que levar algumas atividades para casa, e não é falta de organização, é muito serviço mesmo, ainda tem a situação de chegar e cuidar da casa da família, chega um ponto que o cansaço interfere nas sua atividades do trabalho, porque você não descansa, e no seu convívio social porque esta estressada, irritada porque não descansou. (AZUL)

A Organização Mundial de Saúde (OMS) considera o estresse como uma epidemia global, sendo muito comum no meio dos profissionais de enfermagem, visto que a profissão é técnico cientifica, que oferece cuidado humano e holístico, exigindo destes profissionais embasamento teórico e habilidades cognitivo, psicomotoras e interpessoais. Em contrapartida, as instituições empregadoras oferecem baixa remuneração que somado a sobrecarga de trabalhos pode resultar em alterações psíquicas, baixo rendimento profissional e pessoal. ${ }^{4}$

$\mathrm{Na}$ população pesquisada é possível identificar que a sobrecarga de trabalho causa interferência nas questões profissionais, mas também na qualidade de vida cotidiana. As atividades laborais que excedem o período de trabalho geram estresse e interferem em suas vidas de diversas maneiras, conforme descreve os discursos que seguem:

Atrapalha bastante na vida pessoal porque você chega em casa cansada por que trabalhou, ai você quer descansa a família quer fazer alguma coisa e você acaba querendo descansar devido aquele dia carregado e acaba se prendendo, en tão afeta sim, um monte. (AMARELO)

Pessoal porque não durmo bem de noite, fico estressada, brigo com meu marido, e profissional porque a gente não consegue fazer o serviço direito, não consegue do andamento no serviço, fazer suas atividades básicas do dia a dia, você fica só naquela de tampa buraco. (VERDE)
As várias atividades que acabo tendo que realizar aqui no hospital me consome, sinto que meu desempenho diminuiu junto com a qualidade do meu serviço, a falta de condições no atendimento e pior que afeta a qualidade da minha vida lá fora, não tenho vontade de sair com os amigos, fazer uma academia e às vezes até conversar. (ROSA)

O serviço hospitalar, que o enfermeiro está inserido, se caracteriza por um trabalho intensivo, que exige do funcionário alta produtividade em tempo limitado, muitas vezes em condições inadequadas sejam estruturais ou de processos, acarretando em queda da produtividade, problemas de saúde ás vezes irreversíveis. Não se pode falar de qualidade de produtos e serviços, se seus produtores não têm qualidade de vida. ${ }^{13}$

Qualidade de vida diz respeito às necessidades e realizações profissionais e pessoais inerentes ao ser humano. Fatores do ambiente de trabalho impactam na saúde e desempenho do indivíduo, sendo que harmonizar as necessidades da empresa com as do trabalhador melhoram a produtividade da empresa e consequentemente para o profissional, sua qualidade de vida no trabalho. ${ }^{14}$

\section{Uso de psicotrópicos, sua relação com o trabalho}

Esta categoria retrata se o enfermeiro faz uso de medicação psicoativa e qual foi a indicação médica. Dentre a população pesquisada, 70,5\% afirmam fazer uso de alguma medicação, sendo $30 \%$ de uso contínuo com acompanhamento médico e $44 \%$ de maneira descontínua e automedicação. Nos discursos fica evidenciado que a busca e utilização pela medicação tem relação mútua com a sobrecarga de trabalho, ansiedade, cansaço e estresse, conforme demonstra os discursos a seguir:

A indicação foi por estresse e depressão, eu utilizo um antidepressivo e um ansiolítico. (ROXO)

Quando estou muito estressada eu uso, já usei sertralina, e fluoxetina, quando vejo que estou estressada tomo por conta sem indicação médica, visto melhora interrompo uso só nos picos de estresses e não continuo. (AMARELO)

Eu uso algumas medicações, antidepressivo, ansiolítico que o médico indicou por eu não conseguir dormir, muita ansiedade, irritada ,não tinha vontade de fazer nada, trabalhava pela necessidade mesmo. (AZUL)

Faço uso de analgésicos e medicação para dormir por minha conta, quando estou muito cansada, que não durmo por que tem muito trabalho ou então quando vem a dor nas pernas e na coluna. (ROSA)

O trabalhador de enfermagem soma elevado número de profissionais que sofrem desgastes físicos e psíquicos devido à exaustão enfrentada no trabalho. Passam a utilizar substâncias psicoativas, mesmo que sem orientação médica, na busca de alívio da sobrecarga de trabalho físico e emocional que compromete a qualidade de vida do profissional e as atividades realizadas. ${ }^{12}$

Tendo as condições de trabalho, como fator de- 
sencadeador do uso de substâncias psicoativas pelos trabalhadores de enfermagem afirma que o enfermeiro em seu cotidiano está exposto a elevada carga de trabalho, podendo causar sérios danos à saúde do trabaIhador, visto que os mesmos convivem anos realizando esforço repetitivo que vão de baixa à alta complexidade, exigindo maior desempenho de suas competências e sobrecarga de trabalho. ${ }^{11}$

Os fatores psicossociais no trabalho, que são os que interagem com elementos do ambiente de trabalho e enfatizam as necessidades do trabalhador, são consideráveis para saúde do trabalhador. Podendo resultar em fatores de risco ou de promoção da saúde nas áreas social, psicológica e física. ${ }^{13}$

Ansiedade é um estado psíquico-emocional que acarreta desordem no sistema fisiológico, emocional e espiritual. Quando em nível elevado pode tornar o trabalhador incapacitante, pois a pressão e o estresse vivenciado no ambiente de trabalho, não impede que o profissional almeje dar o seu melhor para garantir seu emprego mesmo frente à sobrecarga de trabalho, conflitos, desvalorização profissional, dupla jornada de trabalho, relacionamento interpessoal deficiente, mas todos estes fatores contribui para o profissional fazer uso de substâncias psicoativas. ${ }^{12}$

\section{CONSIDERACִÕES FINAIS}

Os enfermeiros participantes da pesquisa enfrentam situações-de estresse laboral, resultantes de condições e ambiente não adequados de trabalho, com consequências negativas para a saúde e consequentemente para sua qualidade de vida. Na tentativa de minimizar a sobrecarga física e psíquica, buscam as substâncias psicoativas por acreditarem que vivenciam uma situação temporal e que os tratamentos com estas substâncias os tornam aptos para desenvolver suas atividades em âmbito profissional e pessoal.

É necessário que os gestores percebam, precocemente, os fatores de risco e de promoção da saúde do trabalhador enfermeiro, a fim de estabelecer as condições de saúde no ambiente de trabalho, de forma a serem priorizadas e tratadas como ponto de partida para qualidade de vida do trabalhador.

Entende-se que as discussões sobre a temática devam ser expandidas, reforçando a importância de se investir em políticas públicas e institucionais, enfatizando as estruturas de trabalho. Este estudo nos traz a necessidade de repensar sobre o profissional enfermeiro, indivíduo trabalhador, como um ser único e que requer atenção e valorização.

\section{REFERÊNCIAS}

1. Ferreira MCR, Martino MMF. $O$ estresse do enfermeiro: análise das publicações sobre o tema, Rev. Ciênc. Méd., Campinas 2006;15(3):241-8.
2. Schmoeller R, Trindade LL, Neis MB, Gelbcke FL, et al. Cargas de trabalho e condições de trabalho da enfermagem: revisão integrativa. Revista Gaúcha Enfermagem, Porto Alegre 2011; 32(2):368-77. doi: 10.1590/S1983-14472011000200022.

3. Trindade L.L, Lautert L. Síndrome de burnout entre os trabalhadores da estratégia de saúde da família. Rev. Esc. Enf. USP 2010;44(2):274-279. doi: 10.1590/ S0080-62342010000200005.

4. França FG, Ferrari R. Síndrome de burnout e os aspectos sócio demográficos em profissionais de enfermagem. Acta Paulista de Enfermagem 2012;25(5):743-748. doi: 10.1590/ S0103-21002012000500015.

5. Galindo RH, Feliciano KVO, Lima RAS. Síndrome de burnout entre enfermeiros de um hospital geral da cidade do Recife. Revista da Escola de Enfermagem da USP 2012;46(2):420427. doi: 10.1590/S0080-62342012000200021.

6. Kaminski ML. Uso de psicofármacos em trabalhadores de hospitais universitários de Pelotas/RS: prevalência e fatores associados [dissertação] Pelotas: Universidade Católica de Pelotas; 2010. http://tede.ucpel.edu.br:8080/tede/handle/ tede/289.

7. Meneghini F, Paz AA, Lautert L. Fatores ocupacionais associados aos componentes sa síndrome de burnout em trabalhadores de enfermagem. Texto Contexto Enferm 2011;20(2):225-33.

8. Minayo MCS. (Org.). Pesquisa social: teoria, método e criatividade. 18. ed. Petrópolis: Vozes; 2001.

9. Elias MA, Navarro VL. A relação entre o trabalho, a saúde e as condições de vida: negatividade e positividade no trabalho das profissionais de enfermagem de um hospital escola. Rev Latino-am Enfermagem 2006;14(4):517-25. doi: 10.1590/ S0104-11692006000400008.

10. Zeitorine RCG, Martins ERC. As condições de trabalho como fator desencadeador do uso de substâncias psicoativas pelos trabalhadores de enfermagem. Esc Anna Nery Rev Enferm 2007;11(4):639-44. doi: 10.1590/S141481452007000400013.

11. Pinto WM, Silva CDL. Riscos ocupacionais no ambiente hospitalar: fatores que favorecem a sua ocorrência na equipe de enfermagem. Saúde Coletiva em Debate 2012;2(1):62-29.

12. Dissen CM, Beck CLC, Vieira TG. Adoecimento e uso de medicamentos psicoativos entre trabalhadores de enfermagem de unidades de terapia intensiva. Rev Enferm 2013;3(2):205-214. doi: 10.5902/217976927538.

13. Presoto LH. Promoção da Saúde e qualidade de vida do trabalhador em hospitais estaduais da cidade de são paulo [tese]. São Paulo: Universidade de São Paulo-Faculdade de Saúde Pública; 2008.

14. Cheremeta M, Pedroso B, Pillati LA, Kovaleski JL. Construção da versão abreviada OWLQ-78: um instrumento de avaliação da qualidade de vida no trabalho. Revista Brasileira de Qualidade de Vida 2011;3(1):01-15. doi: 10.3895/S217508582011000100001.

Como citar: VIEIRA, Graziela Clementina Galvani et al. Uso de psicotropicos pelo enfermeiro: sua relação com o trabalho. Cinergis, Santa Cruz do Sul, v. 17, n. 3, set. 2016. ISSN 2177-4005. Disponivel em: <https://online.unisc.br/seer/index.php/ cinergis/article/view/8118>. Acesso em: 11 out. 2016. doi:http://dx.doi.org/10.17058/cinergis.v17i3.8118. 